\title{
Neutrophil-lymphocyte ratio predicts survival in pancreatic neuroendocrine tumors
}

\author{
GUOPEI LUO ${ }^{1-3^{*}}$, CHEN LIU $^{1-3^{*}}$, HE CHENG $^{1-3^{*}}$, KAIZHOU JIN ${ }^{1-3}$, MENG GUO $^{1-3}$, \\ YU LU ${ }^{1-3}$, JIANG LONG ${ }^{1-3}$, JIN XU ${ }^{1-3}$, QUANXING NI ${ }^{1-3}$, JIE CHEN ${ }^{4}$ and XIANJUN YU ${ }^{1-3}$ \\ ${ }^{1}$ Department of Pancreatic Surgery, Fudan University Shanghai Cancer Center; ${ }^{2}$ Department of Oncology, \\ Shanghai Medical College of Fudan University; ${ }^{3}$ Pancreatic Cancer Institute, Fudan University, Shanghai 200032; \\ ${ }^{4}$ Department of Gastroenterology, The First Affiliated Hospital, Sun Yat-Sen University, \\ Guangzhou, Guangdong 510080, P.R. China
}

Received December 20, 2016; Accepted January 31, 2017

DOI: $10.3892 / \mathrm{ol} .2017 .5716$

\begin{abstract}
Although the prognostic role of neutrophil-lymphocyte ratio (NLR) has been confirmed in a variety of tumors, the prognostic role of NLR in pancreatic neuroendocrine tumors (PNETs) has not been examined. The present study was performed to assess the role of NLR as a prognostic factor in patients with PNETs. Clinical data were retrospectively retrieved from a single institution. The best cut-off value for baseline NLR levels was determined by the receiver operating characteristic (ROC) curve and area under the ROC curve. The primary event was overall survival and event times were assessed by the Kaplan-Meier method. Potential factors associated with the elevation of NLR in PNETs were examined. A total of 165 consecutive patients with pathologically confirmed PNETs were included in this study. The cutoff value of NLR was 2.4 by ROC curve (area under ROC curve, 0.70 ). NLR $>2.4$ was found to be a poor prognostic factor in the univariate and multivariate analyses. Patients with a NLR value $>2.4$ had a higher proportion of tumor size at $>3 \mathrm{~cm}(\mathrm{P}=0.001)$, TNM stage III or IV $(\mathrm{P}=0.019)$, and $\mathrm{G} 2 / \mathrm{G} 3(\mathrm{P}=0.003)$. We concluded that NLR is an independent predictor of overall survival for patients with PNETs. Aberrant elevation of NLR identifies high-risk patients with aggressive characteristics.
\end{abstract}

\section{Introduction}

Pancreatic neuroendocrine tumors (PNETs) are rare but clinical important tumors with an incidence of approximately

Correspondence to: Dr Xianjun Yu or Dr Guopei Luo, Department of Pancreatic Surgery, Fudan University Shanghai Cancer Center, 270 Dong'An Road, Shanghai 200032, P.R. China

E-mail: yuxianjun@fudanpci.org

E-mail: luoguopei@hotmail.com

*Contributed equally

Key words: pancreatic neuroendocrine tumor, prognosis, pancreatic neuroendocrine tumors, neutrophil-lymphocyte ratio
1 in 100,000 of the population, accounting for $1-2 \%$ of all pancreatic tumors in incidence and $10 \%$ in prevalence (1-4). They are broadly categorized as functioning or non-functioning tumors based on their clinical manifestation (5). Unlike functioning neoplasms, non-functioning PNETs are often detected at an advanced stage due to the lack of specific symptoms (6). PNETs are highly heterogeneous neoplasms presenting a spectrum of biologic behavior $(7,8)$. Aggressive progression can even be observed in incidentally detected and small tumors (9). Potential prognostic factors, including mitoses, vascular invasion, metastasis, necrosis, Ki-67 expression, and nuclear grade, are mostly based on pathological examination $(2,3,10,11)$. Therefore, circulating biomarkers are needed to predict their malignant behavior and prognosis.

Neutrophil-lymphocyte ratio (NLR) is derived from the absolute neutrophil count divided by the absolute lymphocyte count and is a routinely used, reliable, and convenient marker (12). It is an index of systemic inflammation, which is a common phenomenon and prognostic determinant of cancer (12). In recent years, increasing evidence has demonstrated the role of NLR in evaluating treatment response and predicting prognosis in various types of cancer (13-17). For example, in pancreatic adenocarcinoma, NLR may be used to assess survival in unselected cohorts, patients with advanced diseases treated with chemotherapy, and patients undergoing curative surgery (13-16). In addition, NLR was statistically significantly associated with tumor stage, differentiation, performance status, CA19-9, C-reactive protein, and albumin levels in pancreatic adenocarcinoma (16). However, the prognostic role of NLR in PNETs has not been evaluated.

The present study was performed to examine the role of blood NLR as a prognostic factor in a large cohort of patients with PNETs. Potential clinicopathological factors associated with the abnormal elevation of NLR in PNETs were also evaluated.

\section{Materials and methods}

Patients. The databases of Shanghai Cancer Center, Fudan University (Shanghai, China) were collected to identify potential patients with pathological confirmed PNETs between 
2006 and 2015. Data were retrieved regarding patient demographics, symptoms, tumor size, location, functioning status, histologic grade, lymph node involvement, vessel invasion, nerve invasion, and TNM stages. Positive symptoms included abdominal and back pain, weight loss, nausea, vomiting, fatigue and jaundice. Patients with functioning PNETs or patients with non-functioning PNETs and without the above mentioned symptoms were viewed as incidental PNETs (18). The patients were staged based on the 7th edition of American Joint Committee on Cancer (AJCC) TNM staging system. Tumors were categorized as G1, G2, G3 according to the 2010 World Health Organization (WHO) classification (based on the Ki-67 index and the mitotic index) (19). Patients were followed up $>18$ months or until death. The laboratory data including neutrophil and lymphocyte were obtained before major treatments within 2 weeks. The NLR was calculated by the absolute neutrophil count divided by the absolute lymphocyte count. The receiver operating characteristic (ROC) curve and area under the ROC curve were applied to select the best cut-off values for baseline NLR. The current study was approved by the ethics committee of Shanghai Cancer Center, Fudan University.

Statistical analysis. Univariate and multivariate analyses based on a Cox proportional hazards model were used to analyze potential prognostic factors. Factors with a $\mathrm{P}<0.05$ in the univariate analysis were further included in the multivariate analysis. The effect of the NLR and other factors on survival was estimated using the Kaplan-Meier method. Pearson's $\chi^{2}$ test or Fisher's exact test was used to analyze categorical data as appropriate. The analysis was performed using the STATA 12.0 statistical software package (StataCorp LP, College Station, TX, USA). A two-sided $\mathrm{P}<0.05$ was considered to indicate a statistically significant difference.

\section{Results}

Patients data and survival analysis. A total of 165 consecutive patients with pathologically confirmed PNETs were included in the present study (Table I). The median age was 52, with $58.2 \%$ of patients having an age $>50$. More than $50 \%$ of patients were female, with a female-to-male ratio of 1.2:1. A total of 68 patients $(41.2 \%)$ had tumors located at the head of the pancreas and 97 patients $(58.8 \%)$ at the body, or tail of the pancreas, or whole pancreas. The median size was $4 \mathrm{~cm}$, with $>60 \%$ of cases having tumors $>3 \mathrm{~cm}$ in diameter. More than $60 \%$ of patients had stage I or II tumors. Nearly $50 \%$ of the patients had G1 tumors (G1 46.3\%, G2 42.6\%, G3 11.0\%) and 18 patients $(10.9 \%)$ had functioning diseases. Nearly half of the patients $(47.3 \%)$ had PNETs with symptoms.

The cut-off value of NLR as a prognostic predictor of patients with PNETs was 2.4 by ROC curve (area under ROC curve, 0.70 , sensitivity $71.4 \%$, specificity $76.5 \%$, Fig. 1 ), with $28.5 \%$ of patients having NLR levels higher than the selected cut-off value. Sixty-five patients were followed up $<18$ months and 1 patient had perioperative death and 10 patients were lost to follow-up $(10 / 165,6.1 \%)$, leaving 89 patients for the survival analysis. The univariate analysis, TNM stage III or IV $(\mathrm{HR}=14.33, \mathrm{P}<0.01), \mathrm{NLR}>2.4(\mathrm{HR}=7.15$, $\mathrm{P}=0.003), \mathrm{G} 3$ diseases $(\mathrm{HR}=17.82, \mathrm{P}<0.01)$, and incidental
Table I. Demographics and clinical characteristics.

\begin{tabular}{lcr}
\hline $\begin{array}{l}\text { Demographic or } \\
\text { clinical characteristic }\end{array}$ & Parameter & No. $(\%)$ \\
\hline Age & $\leq 50$ & $69(41.8)$ \\
& $>50$ & $96(58.2)$ \\
Gender & Male & $76(46.1)$ \\
& Female & $89(53.9)$ \\
Location & Head & $68(41.2)$ \\
& Others & $97(58.8)$ \\
Size (cm) & $\leq 3$ & $57(34.5)$ \\
TNM stage & $>3$ & $108(65.5)$ \\
& I, II & $107(64.8)$ \\
Grade & III, IV & $58(35.2)$ \\
& G1 & $63(46.3)$ \\
Functioning & G2 & $58(42.6)$ \\
Symptom & G3 & $15(11.0)$ \\
& Positive & $18(10.9)$ \\
& Negative & $147(89.1)$ \\
& Positive & $78(47.3)$ \\
& Negative & $87(52.7)$ \\
\hline
\end{tabular}

${ }^{a}$ Only 136 cases had information for grade. TNM, tumor-nodemetastasis.

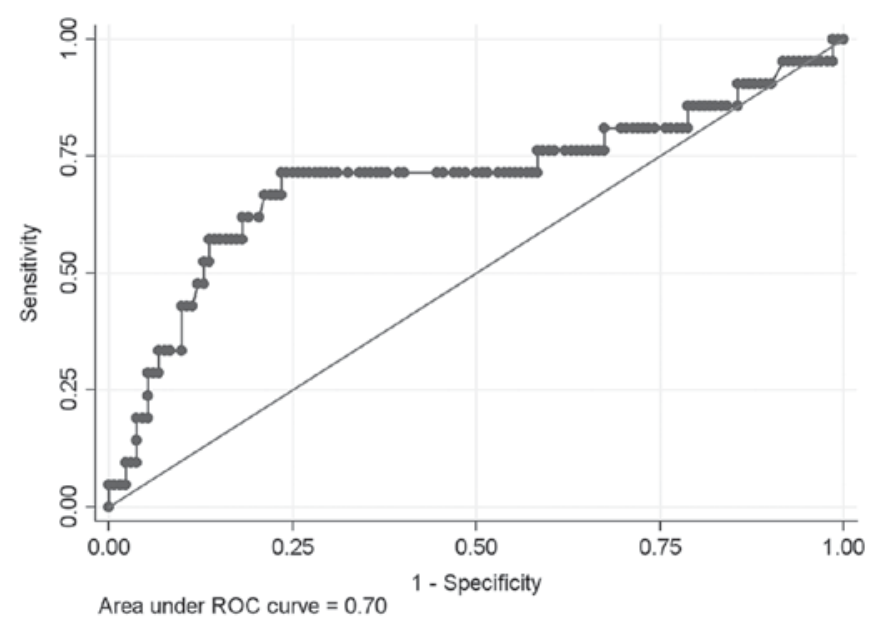

Figure 1. The receiver operating characteristic (ROC) curve and area under the ROC curve for the neutrophil-lymphocyte ratio as a prognostic factor.

PNETs $(\mathrm{HR}=0.27, \mathrm{P}=0.006)$ were prognostic factors for patients' overall survival, whereas gender, age, tumor size, and location were not statistically significantly associated with overall survival (Table II; Fig. 2). In the multivariate analysis, TNM stage III or IV $(\mathrm{HR}=6.70, \mathrm{P}=0.001), \mathrm{NLR}>2.4$ $(\mathrm{HR}=3.60, \mathrm{P}=0.011)$, and $\mathrm{G} 3$ diseases $(\mathrm{HR}=6.31, \mathrm{P}=0.004)$ were poor prognostic factors for overall survival (Table II).

Parameters correlated with baseline NLR levels. The $\chi^{2}$ test was employed to analyze clinical and pathologic factors correlated with baseline NLR levels (NLR $\leq 2.4$ and NLR $>2.4$, 
Table II. Univariate and multivariate analysis for overall survival of all patients using the Cox proportional hazards model ${ }^{\mathrm{a}}$.

\begin{tabular}{|c|c|c|c|c|c|c|c|c|}
\hline \multirow[b]{2}{*}{ Characteristic } & \multirow[b]{2}{*}{ Parameter } & \multirow[b]{2}{*}{ No. } & \multicolumn{3}{|c|}{ Univariate analysis } & \multicolumn{3}{|c|}{ Multivariate analysis } \\
\hline & & & HR & $95 \% \mathrm{CI}$ & P-value & HR & $95 \% \mathrm{CI}$ & P-value \\
\hline \multirow[t]{2}{*}{ Age } & $\leq 50$ & 40 & 1 & - & - & & & \\
\hline & $>50$ & 49 & 0.84 & $0.35-2.01$ & 0.688 & & & \\
\hline \multirow[t]{2}{*}{ Gender } & Male & 38 & 1 & - & - & & & \\
\hline & Female & 51 & 0.56 & $0.23-1.36$ & 0.201 & & & \\
\hline \multirow[t]{2}{*}{ Size $(\mathrm{cm})$} & $\leq 3$ & 35 & 1 & - & - & & & \\
\hline & $>3$ & 54 & 2.06 & $0.75-5.68$ & 0.140 & & & \\
\hline \multirow[t]{2}{*}{ Location } & Head & 33 & 1 & - & - & & & \\
\hline & Others & 56 & 0.87 & $0.36-2.13$ & 0.761 & & & \\
\hline \multirow[t]{2}{*}{ TNM stage } & $\mathrm{I}, \mathrm{II}$ & 63 & 1 & - & - & 1 & - & - \\
\hline & III, IV & 26 & 14.33 & $4.75-41.20$ & 0.001 & 6.70 & $2.12-21.15$ & 0.001 \\
\hline \multirow[t]{2}{*}{ NLR } & $\leq 2.4$ & 61 & 1 & - & - & 1 & - & - \\
\hline & $>2.4$ & 28 & 7.15 & $2.72-18.74$ & 0.001 & 3.60 & $1.33-9.71$ & 0.011 \\
\hline \multirow[t]{3}{*}{ Grade } & G1, G2 & 63 & 1 & - & - & 1 & - & - \\
\hline & G3 & 12 & 17.82 & $5.64-56.29$ & 0.001 & 6.31 & $1.83-21.79$ & 0.004 \\
\hline & Unknown & 14 & 6.78 & $2.07-22.24$ & 0.002 & 3.72 & $1.09-12.67$ & 0.036 \\
\hline \multirow[t]{2}{*}{ Symptom } & Positive & 43 & 1 & - & - & 1 & - & - \\
\hline & Negative & 46 & 0.27 & $0.10-0.74$ & 0.006 & 0.57 & $0.19-1.67$ & 0.305 \\
\hline
\end{tabular}

${ }^{\text {aOnly }} 65$ patients followed up $<18$ months and 1 patient had perioperative death and 10 patients were lost to follow-up, leaving 89 patients for the survival analysis. HR, hazard ratio; CI, confidence interval; NLR, neutrophil-lymphocyte ratio; TNM, tumor-node-metastasis.

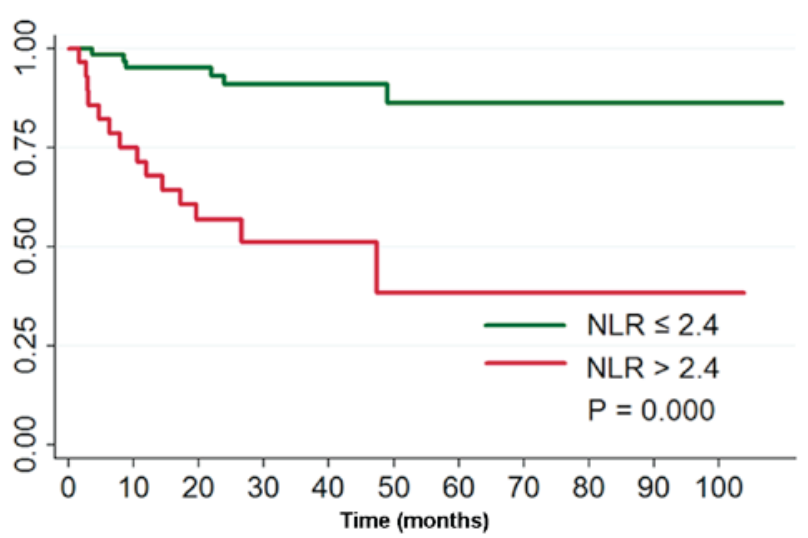

Figure 2. Kaplan-Meier survival curves according to neutrophil-lymphocyte ratio $(\mathrm{NLR}) \leq 2.4$ or NLR $>2.4$.

Table III). A NLR $>2.4$ was statistically significantly associated with tumor size $(\mathrm{P}=0.001)$, TNM stage III or IV $(\mathrm{P}=0.019)$, and tumor grade $(\mathrm{P}=0.003)$, but not with age, gender, location, symptoms, vessel invasion, and nerve invasion. Of note, NLR >2.4 was associated with positive lymph status $(\mathrm{P}=0.067)$ and functioning status $(\mathrm{P}=0.084)$.

\section{Discussion}

To the best of our knowledge, this study is the first to investigate the prognostic role of NLR in PNETs. Using ROC curve, the cut-off value of NLR as a prognostic predictor of patients with PNETs was 2.4. NLR >2.4 was found to be a poor prognostic factor in both univariate and multivariate analyses for patients with PNETs. We also showed that an NLR $>2.4$ was statistically significantly associated with tumor size $>3 \mathrm{~cm}$, TNM stage III or IV, and tumor grade. We demonstrated that NLR is a prognostic marker of patients with PNETs which may predict their clinical outcome and aggressive features.

NLR is more widely available and convenient compared with other biomarkers. Therefore, considering its prognostic role in PNETs, NLR may be used to stratify patients with high risk of therapeutic resistance, early recurrence, or metastasis. In addition, NLR has the potential to determine therapeutic strategy, monitor disease progression, and evaluate treatment response.

Mounting evidence has shown that cancer-associated inflammation is a key factor of prognosis in patients with cancer (12). In a study by Hochwald et al, tumor necrosis was correlated strongly with prognosis in patients with PNETs (10). Previous findings demonstrated that a higher NLR level was significantly correlated with a larger tumor size, histologic tumor necrosis, and tumor differentiation (20). In this study, we also showed that NLR was significantly correlated with tumor size, TNM stage, and tumor grade, which are all strongly associated with tumor necrosis.

A variety of markers of systemic inflammation have been evaluated over the past decade for therapeutic response and predicting survival, including NLR, Glasgow prognostic score and its modified version, prognostic index, platelet 
Table III. NLR, patient demographics and clinical characteristics.

\begin{tabular}{|c|c|c|c|c|}
\hline Demographic or clinical characteristic & Parameter & NLR $\leq 2.4$ & NLR $>2.4$ & P-value \\
\hline Age & $\begin{array}{l}\leq 50 \\
>50\end{array}$ & $\begin{array}{l}48 \\
70\end{array}$ & $\begin{array}{l}21 \\
26\end{array}$ & 0.638 \\
\hline Gender & $\begin{array}{c}\text { Male } \\
\text { Female }\end{array}$ & $\begin{array}{l}56 \\
62\end{array}$ & $\begin{array}{l}20 \\
27\end{array}$ & 0.568 \\
\hline Location & $\begin{array}{c}\text { Head } \\
\text { Others }\end{array}$ & $\begin{array}{l}52 \\
66\end{array}$ & $\begin{array}{l}16 \\
31\end{array}$ & 0.238 \\
\hline Size $(\mathrm{cm})$ & $\begin{array}{l}\leq 3 \\
>3\end{array}$ & $\begin{array}{l}50 \\
68\end{array}$ & $\begin{array}{r}7 \\
40\end{array}$ & 0.001 \\
\hline TNM stage & $\begin{array}{c}\text { I, II } \\
\text { III, IV }\end{array}$ & $\begin{array}{l}83 \\
35\end{array}$ & $\begin{array}{l}24 \\
23\end{array}$ & 0.019 \\
\hline Grade & $\begin{array}{c}\text { G1 } \\
\text { G2/G3 }\end{array}$ & $\begin{array}{l}54 \\
46\end{array}$ & $\begin{array}{r}9 \\
27\end{array}$ & 0.003 \\
\hline Lymph status ${ }^{\mathrm{a}}$ & $\begin{array}{l}\text { Positive } \\
\text { Negative }\end{array}$ & $\begin{array}{l}14 \\
56\end{array}$ & $\begin{array}{r}7 \\
10\end{array}$ & 0.067 \\
\hline Vessel invasion ${ }^{\mathrm{a}}$ & $\begin{array}{l}\text { Positive } \\
\text { Negative }\end{array}$ & $\begin{array}{l}15 \\
48\end{array}$ & $\begin{array}{r}6 \\
11\end{array}$ & 0.340 \\
\hline Nerve invasion ${ }^{\mathrm{a}}$ & $\begin{array}{l}\text { Positive } \\
\text { Negative }\end{array}$ & $\begin{array}{l}13 \\
47\end{array}$ & $\begin{array}{r}1 \\
16\end{array}$ & 0.136 \\
\hline Functioning & $\begin{array}{l}\text { Positive } \\
\text { Negative }\end{array}$ & $\begin{array}{r}16 \\
102\end{array}$ & $\begin{array}{r}2 \\
45\end{array}$ & 0.084 \\
\hline Symptom & $\begin{array}{l}\text { Positive } \\
\text { Negative }\end{array}$ & $\begin{array}{l}52 \\
66\end{array}$ & $\begin{array}{l}26 \\
21\end{array}$ & 0.191 \\
\hline
\end{tabular}

${ }^{\text {a}}$ For cases that underwent curative resection only. NLR, neutrophil-lymphocyte ratio, TNM, tumor-node-metastasis.

lymphocyte ratio, and prognostic nutrition index $(21,22)$. Of these markers, NLR is a routinely available and promising marker that can be used to assess systemic inflammation and therapeutic responses $(13,21,22)$. For example, Wang et al found that NLR was the only marker of inflammation for prognosis on multivariate analysis and elevated NLR was better than the modified Glasgow prognostic score, prognostic index, platelet lymphocyte ratio, and prognostic nutrition index for prognostication in patients with pancreatic cancer (22). Another study demonstrated that baseline NLR and NLR, which were used as potential prognostic markers in patients with advanced pancreatic cancer, were altered following treatment with chemotherapy (13). In the current study, we confirm the prognostic role of NLR in patients with PNETs by both univariate and multivariate analyses.

In addition to specific markers in functioning PNETs, there are general biomarkers used to diagnose and monitor functioning and non-functioning PNETs (23). Chromogranin A $(\mathrm{CgA})$ is the most widely used biomarker and has been reported to be elevated in 50-80\% of patients with PNETs. It is an ideal biomarker used to monitor disease progression for cases with CgA elevation (23). However, in a study conducted by Sherman et al, no correlation between $\mathrm{CgA}$ and survival was found in patients with PNETs in a multivariate analysis (24). Pancreatic polypeptide is a 36 amino acid protein secreted by endocrine cells located primarily in the pancreatic head and uncinate process, with a low sensitivity of $31 \%$ in PNETs (25). Neuron-specific enolase is a biomarker with a sensitivity of $33 \%$ and a specificity of $100 \%$ in patients with gastroenteropancreatic neuroendocrine tumors (26). It is also an independent predictor of survival for patients with advanced G1/2 PNETs undergoing peptide receptor radionuclide therapy (27). Pancreastatin is a post-translational fragment of $\mathrm{CgA}$ peptide and has great sensitivity and specificity for detecting PNETs and correlates with survival (24). However, although not varying with proton pump inhibitor as $\mathrm{CgA}$, pancreastatin may be affected by insulin and glucose homeostasis (23). Therefore, NLR has the potential to serve as a supplemental prognostic predictor to these biomarkers.

The current study has several shortcomings. Firstly, despite a relatively large sample size, the retrospective feature of this study may limit its clinical application. Further prospective evidence with large sample size is needed. In addition, NLR is a non-specific marker that could be affected by several confounders, mainly including bacterial inflammation, immunologic response, and anticancer treatments (13). In addition, the predicting role of NLR in combination with other biomarkers including $\mathrm{CgA}$, pancreatic polypeptide, and neuron-specific enolase was not demonstrated. Furthermore, the dynamics of NLR during treatment and follow-up were not presented in the current study. 
In conclusion, baseline NLR is a strong independent predictor of overall survival for patients with PNETs. A high level of NLR has a significant correlation with large tumor size, advanced stage, and high grade. Aberrant elevation of NLR identifies high-risk patients who may require special treatment and close follow-up.

\section{Acknowledgements}

The present study was jointly funded by the National Science Foundation for Distinguished Young Scholars of China (no. 81625016), the National Natural Science Foundation of China (nos. 81372649, 81172276, 81370065 and 81372653), Shanghai Municipal Commission of Health and Family Planning scientific research (no. 20144Y0170), and basic research projects of the Science and Technology Commission of Shanghai Municipality (no. 15JC1401200).

\section{References}

1. Oberg K and Eriksson B: Endocrine tumours of the pancreas. Best Pract Res Clin Gastroenterol 19: 753-781, 2005.

2. Luo G, Liu Z, Guo M, Jin K, Xiao Z, Liu L, Xu J, Zhang B, Liu C, Huang D, et al: ${ }^{18} \mathrm{~F}-\mathrm{FDG}$ PET/CT can be used to detect non-functioning pancreatic neuroendocrine tumors. Int $\mathbf{J}$ Oncol 45: 1531-1536, 2014.

3. O'Grady HL and Conlon KC: Pancreatic neuroendocrine tumours. Eur J Surg Oncol 34: 324-332, 2008.

4. Ricci C, Casadei R, Taffurelli G, D'Ambra M, Monari F, Campana D, Tomassetti P, Santini D and Minni F: WHO 2010 classification of pancreatic endocrine tumors. Is the new always better than the old? Pancreatology 14: 539-541, 2014.

5. Li J, Luo G, Fu D, Jin C, Hao S, Yang F, Wang X, Yao L and Ni Q: Preoperative diagnosis of nonfunctioning pancreatic neuroendocrine tumors. Med Oncol 28: 1027-1031, 2011.

6. Yao JC, Hassan M, Phan A, Dagohoy C, Leary C, Mares JE, Abdalla EK, Fleming JB, Vauthey JN, Rashid A, et al: One hundred years after 'carcinoid': Epidemiology of and prognostic factors for neuroendocrine tumors in 35,825 cases in the United States. J Clin Oncol 26: 3063-3072, 2008.

7. Singh S, Dey C, Kennecke H, Kocha W, Maroun J, Metrakos P, Mukhtar T, Pasieka J, Rayson D, Rowsell C, et al: Consensus recommendations for the diagnosis and management of pancreatic neuroendocrine tumors: Guidelines from a Canadian national expert group. Ann Surg Oncol 22: 2685-2699, 2015.

8. Wiedenmann B, Pavel M and Kos-Kudla B: From targets to treatments: A review of molecular targets in pancreatic neuroendocrine tumors. Neuroendocrinology 94: 177-190, 2011.

9. Haynes AB, Deshpande V, Ingkakul T, Vagefi PA, Szymonifka J, Thayer SP, Ferrone CR, Wargo JA, Warshaw AL and Fernández-del Castillo C: Implications of incidentally discovered, nonfunctioning pancreatic endocrine tumors: Short-term and long-term patient outcomes. Arch Surg 146: 534-538, 2011.

10. Hochwald SN, Zee S, Conlon KC, Colleoni R, Louie O, Brennan MF and Klimstra DS: Prognostic factors in pancreatic endocrine neoplasms: An analysis of 136 cases with a proposal for low-grade and intermediate-grade groups. J Clin Oncol 20: 2633-2642, 2002.

11. Cherenfant J, Talamonti MS, Hall CR, Thurow TA, Gage MK, Stocker SJ, Lapin B, Wang E, Silverstein JC, Mangold K, et al: Comparison of tumor markers for predicting outcomes after resection of nonfunctioning pancreatic neuroendocrine tumors. Surgery 156: 1504-1510, discussion 1510-1511, 2014.
12. Guthrie GJ, Charles KA, Roxburgh CS, Horgan PG, McMillan DC and Clarke SJ: The systemic inflammation-based neutrophil-lymphocyte ratio: Experience in patients with cancer. Crit Rev Oncol Hematol 88: 218-230, 2013.

13. Luo G, Guo M, Liu Z, Xiao Z, Jin K, Long J, Liu L, Liu C, Xu J, Ni Q, et al: Blood neutrophil-lymphocyte ratio predicts survival in patients with advanced pancreatic cancer treated with chemotherapy. Ann Surg Oncol 22: 670-676, 2015.

14. Bhatti I, Peacock O, Lloyd G, Larvin M and Hall RI: Preoperative hematologic markers as independent predictors of prognosis in resected pancreatic ductal adenocarcinoma: Neutrophil-lymphocyte versus platelet-lymphocyte ratio. Am J Surg 200: 197-203, 2010.

15. Stotz M, Gerger A, Eisner F, Szkandera J, Loibner H, Ress AL, Kornprat P, AlZoughbi W, Seggewies FS, Lackner C, et al: Increased neutrophil-lymphocyte ratio is a poor prognostic factor in patients with primary operable and inoperable pancreatic cancer. Br J Cancer 109: 416-421, 2013.

16. Yang JJ, Hu ZG, Shi WX, Deng T, He SQ and Yuan SG: Prognostic significance of neutrophil to lymphocyte ratio in pancreatic cancer: A meta-analysis. World J Gastroenterol 21: 2807-2815, 2015.

17. Paramanathan A, Saxena A and Morris DL: A systematic review and meta-analysis on the impact of pre-operative neutrophil lymphocyte ratio on long term outcomes after curative intent resection of solid tumours. Surg Oncol 23: 31-39, 2014.

18. Luo G, Liu Z, Guo M, Jin K, Xiao Z, Liu L, Liu C, Xu J, Ni Q, Long J, et al: A comprehensive comparison of clinicopathologic and imaging features of incidental/symptomatic non-functioning pancreatic neuroendocrine tumors: A retrospective study of a single center. Pancreatology 15: 519-524, 2015.

19. Mocci E, Milne RL, Méndez-Villamil EY, Hopper JL, John EM, Andrulis IL, Chung WK, Daly M, Buys SS, Malats N, et al: Risk of pancreatic cancer in breast cancer families from the breast cancer family registry. Cancer Epidemiol Biomarkers Prev 22: 803-811, 2013.

20. Viers BR, Houston Thompson R, Boorjian SA, Lohse CM, Leibovich BC and Tollefson MK: Preoperative neutrophillymphocyte ratio predicts death among patients with localized clear cell renal carcinoma undergoing nephrectomy. Urol Oncol 32: 1277-1284, 2014.

21. Ahmad J, Grimes N, Farid S and Morris-Stiff G: Inflammatory response related scoring systems in assessing the prognosis of patients with pancreatic ductal adenocarcinoma: A systematic review. Hepatobiliary Pancreat Dis Int 13: 474-481, 2014.

22. Wang DS, Luo HY, Qiu MZ, Wang ZQ, Zhang DS, Wang FH, $\mathrm{Li} \mathrm{YH}$ and $\mathrm{Xu} \mathrm{RH}$ : Comparison of the prognostic values of various inflammation based factors in patients with pancreatic cancer. Med Oncol 29: 3092-3100, 2012.

23. Landry CS, Cavaness K, Celinski S and Preskitt J: Biochemical prognostic indicators for pancreatic neuroendocrine tumors and small bowel neuroendocrine tumors. Gland Surg 3: 215-218, 2014.

24. Sherman SK, Maxwell JE, O'Dorisio MS, O'Dorisio TM and Howe JR: Pancreastatin predicts survival in neuroendocrine tumors. Ann Surg Oncol 21: 2971-2980, 2014.

25. Walter T, Chardon L, Chopin-laly X, Raverot V, Caffin AG, Chayvialle JA, Scoazec JY and Lombard-Bohas C: Is the combination of chromogranin A and pancreatic polypeptide serum determinations of interest in the diagnosis and follow-up of gastro-entero-pancreatic neuroendocrine tumours? Eur J Cancer 48: 1766-1773, 2012.

26. Seregni E, Ferrari L, Bajetta E, Martinetti A and Bombardieri E: Clinical significance of blood chromogranin A measurement in neuroendocrine tumours. Ann Oncol 12 (Suppl 2): S69-S72, 2001.

27. Ezziddin S, Khalaf F, Vanezi M, Haslerud T, Mayer K, Al Zreiqat A, Willinek W, Biersack HJ and Sabet A: Outcome of peptide receptor radionuclide therapy with $177 \mathrm{Lu}$-octreotate in advanced grade 1/2 pancreatic neuroendocrine tumours. Eur J Nucl Med Mol Imaging 41: 925-933, 2014. 